\title{
Y-Box-binding protein-1 is a promising predictive marker of radioresistance and chemoradioresistance in nasopharyngeal cancer
}

\author{
Wei-Lin Tay ${ }^{1}$, George Wai-Cheong Yip ${ }^{1}$, Puay-Hoon Tan ${ }^{1,2}$, Ken Matsumoto ${ }^{3}$, Richard Yeo ${ }^{4}$, \\ Tze-Pin Ng${ }^{5}$, Srinivasan Dinesh Kumar ${ }^{1}$, Masafumi Tsujimoto ${ }^{3}$ and Boon-Huat Bay ${ }^{1}$ \\ ${ }^{1}$ Department of Anatomy, Yong Loo Lin School of Medicine, National University of Singapore, Singapore; \\ ${ }^{2}$ Department of Pathology, Singapore General Hospital, Singapore; ${ }^{3}$ Laboratory of Cellular Biochemistry, \\ Institute of Physical and Chemical Research (RIKEN), Saitama, Japan; ${ }^{4}$ Department of Radiation Oncology, \\ National Cancer Centre, Singapore and ${ }^{5}$ Department of Psychological Medicine, National University
}

Hospital, Singapore

\begin{abstract}
The Y-Box-binding protein-1, a member of the cold-shock domain DNA- and RNA-binding protein superfamily, is known to mediate chemoresistance. The aim of this study was to determine the expression of Y-Box-binding protein-1 in nasopharyngeal cancer in vitro and in tumor tissue samples as well as analyze the clinicopathological significance of Y-Box-binding protein-1 expression in nasopharyngeal cancer, in particular as a predictor of outcome after treatment. The Y-Box-binding protein-1 expression profile was evaluated at the mRNA and protein levels in poorly differentiated CNE-2 nasopharyngeal cancer cells by real-time RT-PCR, western blot analysis and immunohistochemistry. Y-Box-binding protein-1 expression in 143 nasopharyngeal cancer specimens was examined by immunohistochemistry and correlated with clinicopathologic parameters. Y-Box-binding protein-1 mRNA and protein were found to be expressed in CNE-2 nasopharyngeal cancer cells in vitro. Of 143 patient tissue sections, $137(96 \%)$ were stained positive for the Y-Box-binding protein-1 protein. Y-Box-binding protein-1 immunostaining was observed to be predominantly cytoplasmic. A higher recurrence of nasopharyngeal cancer was found in patients whose tissues had increased Y-Box-binding protein-1 expression $(P<0.001)$. The Cox proportionate hazard regression model also established that high Y-Box-binding protein-1 immunoreactivity was significantly correlated with increased risk $(2.13$ times) of recurrence as compared to low Y-Box-binding protein-1 immunoreactivity $(P=0.01)$. Within groups of patients treated by radiotherapy or chemoradiotherapy, recurrent cases had significantly higher Y-Box-binding protein-1 expression than nonrecurrent cases $(P<0.001$ and $P=0.0035$, respectively). These data suggest that Y-Box-binding protein-1 expression has clinicopathological significance with potential as a predictive marker of recurrence in nasopharyngeal cancer patients who undergo radiotherapy or chemoradiotherapy.
\end{abstract}

Modern Pathology (2009) 22, 282-290; doi:10.1038/modpathol.2008.181; published online 31 October 2008

Keywords: nasopharyngeal carcinoma; Y-Box-binding protein-1; immunohistochemistry; radiotherapy; chemoradiotherapy

Nasopharyngeal cancer is a tumor of epithelial origin that typically originates in the pharyngeal recess of the nasopharynx. The multifactorial etiology

Correspondence: Dr B-H Bay, MBBS, PhD, Department of Anatomy, Yong Loo Lin School of Medicine, National University of Singapore, 4 Medical Drive, Blk MD10, Singapore 117597, Singapore or Dr P-H Tan, MBBS, FRCPA, Department of Pathology, Singapore General Hospital, Outram Road, Singapore 169608, Singapore.

E-mail: antbaybh@nus.edu.sg or tan.puay.hoon@sgh.com.sg

Received 30 June 2008; revised and accepted 08 October 2008; published online 31 October 2008 of nasopharyngeal cancer includes genetic predisposition, Epstein-Barr virus (EBV) infection, and exposure to environmental and dietary carcinogens. More than $80 \%$ of nasopharyngeal cancer patients are from China, Southeast Asia and other Asian countries whereas this cancer is rare in other parts of the world, with sporadic cases occurring in America and Europe. ${ }^{1}$ Nasopharyngeal cancer was initially classified by the WHO (World Health Organization) in 1978 into three categories based on the degree of differentiation, viz., keratinizing squamous cell carcinoma (WHO Type 1), and nonkeratinizing 
carcinoma which was further subdivided into the differentiated subtype (WHO Type 2) and undifferentiated subtype (WHO Type 3) before the recent addition of another category: basaloid squamous cell carcinoma. $^{2}$

WHO Type 3 nasopharyngeal cancer is the most common histopathological type in endemic areas such as Southern China where it accounts for more than $97 \%$ of nasopharyngeal cancer cases. On the other hand, WHO Type 1 nasopharyngeal cancer is more prevalent in Western countries where it comprises up to $50 \%$ of nasopharyngeal cancer diagnosed but less than $5 \%$ in endemic areas. ${ }^{3,4}$ Radiation therapy is the mainstay of treatment for locally and regionally confined stages of nasopharyngeal cancer. $^{5}$ Both WHO Type 2 and Type 3 nasopharyngeal cancers are generally more radiosensitive and have a higher local control rate after radiotherapy than WHO Type 1 but are also more likely to undergo distant metastasis. ${ }^{6}$ Although nasopharyngeal cancer has remarkable radiosensitivity and chemosensitivity in the early stages of treatment due to p53 functionality and retention of clonality, there is usually resistance to these treatment modalities in the more advanced stages. ${ }^{7}$ Radiotherapy has been integrated with chemotherapy in locally advanced nasopharyngeal cancer, using the chemotherapeutic drug cisplatin in combination with fluorouracil. ${ }^{7-9}$

The Y-box-binding protein-1 (YB-1) represents the most evolutionarily conserved nucleic-acid-binding protein currently known. ${ }^{10}$ It is a member of the coldshock domain DNA- and RNA-binding protein superfamily which is involved in transcriptional and translational control. ${ }^{11}$ YB-1 is a multifunctional protein involved in cell proliferation, apoptosis and DNA replication. YB-1 upregulates multidrug resistance 1 (mdr1) gene transcription which encodes for P-glycoprotein in response to genotoxic stress. ${ }^{11-14}$ P-glycoprotein is known to be involved in the efflux of xenobiotics in cells, thus inducing chemoresistance to numerous anticancer agents.

Hence, the aim of this study was to evaluate the expression of YB-1 in CNE-2 poorly differentiated nasopharyngeal cancer cells in vitro at both mRNA and protein levels and nasopharyngeal cancer tissue samples by immunohistochemistry. We also correlated YB-1 protein expression with clinicopathological parameters and analyzed the expression of YB-1 expression with the outcome of radiotherapy and chemoradiotherapy in nasopharyngeal cancer patients.

\section{Materials and methods}

\section{Cell Culture}

Poorly differentiated CNE-2 nasopharyngeal cancer cells were routinely maintained in specialized nasopharyngeal cancer medium containing RPMI1640 supplemented with $10 \%$ fetal bovine serum
(Hyclone), $2 \mathrm{mM}$ sodium pyruvate, $2 \mathrm{mM}$ penicillinstreptomycin L-glutamine (Invitrogen) and $2 \mathrm{mM}$ minimum essential media nonessential amino acids solution (Invitrogen). MDA-MB-231 breast cancer cells were cultured in RPMI-1640 supplemented with $10 \%$ FBS, $100 \mathrm{U} / \mathrm{ml}$ penicillin and $100 \mu \mathrm{g} / \mathrm{ml}$ streptomycin (Invitrogen). Both cell lines were grown in a humidified atmosphere of $5 \% \mathrm{CO}_{2}$ at $37^{\circ} \mathrm{C}$.

\section{Clinical Materials}

The study population comprised tissue samples from pretreatment endoscopic biopsies of 143 Chinese patients diagnosed with nasopharyngeal cancer, who underwent treatment at Singapore General Hospital between 2000 and 2007. Biopsy sections were cut from formalin-fixed, paraffinembedded tissue at a thickness of $4 \mu \mathrm{m}$ and mounted on 3-aminopropyl-tri-ethoxysilane (APES) slides. The study was approved by the Institutional Review Board, Singapore General Hospital. The age of the patients ranged from 14 to 82, with a median age of 50 years. A total of 4 patients $(3 \%)$ were diagnosed with WHO Type 1 nasopharyngeal cancer, $8(6 \%)$ with WHO Type 2 nasopharyngeal cancer and 131 (92\%) had WHO Type 3 nasopharyngeal cancer. Clinicopathological data which included AJCC staging, tumor staging, nodal status and distant metastasis were only available for 135 patients (Table 1). A total of 70 patients were treated for nasopharyngeal cancer by radiotherapy whereas 64 patients were treated with radiotherapy and concurrent chemotherapy (chemoradiotherapy) using the cytotoxic drugs cisplatin and 5-fluorouracil. One patient received chemotherapy only and another received radiotherapy and adjuvant chemotherapy. Some patients received neoadjuvant chemotherapy prior to concurrent chemoradiotherapy but these cases were classified as having received chemoradiotherapy for the purpose of simplification. The median follow-up of patients was 750 days and 69 patients had recurrent tumors. The median number of days to recurrence was 566 days. A total of 12 patients died during follow-up, out of which 10 were recurrent cases.

\section{Real-Time RT-PCR}

Total RNA was extracted from cells that have reached $80-90 \%$ confluency in a $75 \mathrm{~cm}^{2}$ flask using the RNeasy Mini Kit (Qiagen) in accordance with the manufacturer's protocol. Extracted RNA was converted into first-strand cDNA using SuperScript ${ }^{\mathrm{TM}}$ III Reverse Transcriptase and random hexamers from the SuperScript ${ }^{\mathrm{TM}}$ III First-Strand Synthesis System for RT-PCR (Invitrogen). Real-time PCR was performed with the Lightcycler (Roche), using QuantiTect SYBR Green PCR Master Mix (Qiagen) which provided a final concentration of $2.5 \mathrm{mM} \mathrm{MgCl}_{2}$, and $0.5 \mu \mathrm{M}$ of each primer. The primers for the $Y B-1$ gene 
Table 1 Association between YB-1 immunoreactive score and clinicopathological parameters

\begin{tabular}{|c|c|c|c|c|}
\hline \multirow[t]{2}{*}{ Clinicopathological factor } & \multicolumn{4}{|c|}{$\begin{array}{l}\text { Patients with intensity-percentage } \\
\text { score } \geq 200\end{array}$} \\
\hline & No. of patients & $\%$ & $\mathrm{n}$ & $\mathrm{P}$ \\
\hline \multicolumn{5}{|l|}{ Gender } \\
\hline Male & 98 & 40 & 39 & 0.62 \\
\hline Female & 37 & 35 & 13 & \\
\hline \multicolumn{5}{|l|}{ Age (years) } \\
\hline$<45$ & 40 & 50 & 20 & 0.15 \\
\hline $45-54$ & 44 & 30 & 13 & \\
\hline$\geq 55$ & 51 & 37 & 19 & \\
\hline \multicolumn{5}{|l|}{ Histological subtypes } \\
\hline WHO Type 1 and Type 2 & 12 & 42 & 5 & \\
\hline WHO Type 3 & 123 & 38 & 47 & 0.52 \\
\hline \multicolumn{5}{|l|}{ AJCC staging ${ }^{\mathrm{a}}$} \\
\hline 1 & 9 & 44 & 4 & \\
\hline 2 & 30 & 43 & 13 & \\
\hline 3 & 50 & 28 & 14 & \\
\hline 4 & 42 & 48 & 20 & 0.24 \\
\hline \multicolumn{5}{|l|}{ Tumor stage ${ }^{\mathrm{b}}$} \\
\hline $\mathrm{T} 1$ & 21 & 48 & 10 & \\
\hline $\mathrm{T} 2$ & 50 & 36 & 18 & \\
\hline T3 & 34 & 32 & 11 & \\
\hline $\mathrm{T} 4$ & 25 & 48 & 12 & 0.51 \\
\hline \multicolumn{5}{|l|}{ Nodal status ${ }^{\mathrm{b}}$} \\
\hline No & 33 & 33 & 11 & \\
\hline N1 & 33 & 39 & 13 & \\
\hline N2 & 48 & 38 & 18 & \\
\hline N3 & 16 & 56 & 9 & 0.48 \\
\hline \multicolumn{5}{|l|}{ Distant metastasis ${ }^{\mathrm{a}}$} \\
\hline Mo & 123 & 41 & 50 & \\
\hline M1 & 8 & 13 & 1 & 0.11 \\
\hline
\end{tabular}

${ }^{\mathrm{a}}$ Unavailable information for 4 cases.

${ }^{\mathrm{b}}$ Unavailable information for 5 cases.

were AAGTGATGGAGGGTGCTGAC (forward) and TTCTTCATTGCCGTCCTCTC (reverse). The primers for the housekeeping gene glyceraldehyde-3-phosphate dehydrogenase (G3PDH) were GAAGGTGAA GGTCGGAGTCAACG (forward) and TGCCATGGG TGGAATCATATTGG (reverse). Cycling conditions were: $15 \mathrm{~min}$ at $95^{\circ} \mathrm{C}, 45$ cycles at $94^{\circ} \mathrm{C}$ for $15 \mathrm{~s}$, annealing at $60^{\circ} \mathrm{C}$ for $25 \mathrm{~s}$, extension at $72^{\circ} \mathrm{C}$ for $12 \mathrm{~s}$. Melting curve analysis was subsequently performed to verify the specificity of the amplicon. The specificity of the YB-1 and G3PDH primers were also verified by running the amplicons on a $1 \%$ agarose gel. The $2^{-\Delta \Delta C_{\mathrm{T}}}$ method for the quantification of mRNA was used to analyze the data.

\section{Western Blot Analysis}

Proteins from CNE-2 cells and MDA-MB-231 cells were extracted using cell lysis buffer M-PER ${ }^{\circledR}$ Mammalian Protein Extraction Reagent with Halt
Protease Inhibitor Cocktail and EDTA solution (Pierce) according to manufacturer's instructions and quantified using the Microtiter Bio-Rad Protein Assay protocol (Bio-Rad Laboratories). Bovine serum albumin diluted in nanopure water to a range of concentrations was used as a protein standard. Each of protein samples $(20 \mu \mathrm{g})$ from CNE-2 cells and MDA-MB-231 cells were analyzed by SDSpolyacrylamide gel electrophoresis. Following electrophoresis, the protein was transferred onto a polyvinylidene difluoride membrane by electroblotting for $45 \mathrm{~min}$ at $15 \mathrm{~V}$. After overnight incubation in $5 \%$ nonfat milk in $0.1 \%$ Tween-20 in Tris-buffered saline (TBST; Tris, $\mathrm{NaCl}$ ) at $4^{\circ} \mathrm{C}$ with shaking to block nonspecific binding and subsequent washes with TBST, the membrane was incubated with antiYB-1 antibody (1:1000) for $1.5 \mathrm{~h}$ at room temperature. The anti-YB-1 antibody was raised in a rabbit by injecting a synthetic peptide K13 having the sequence MSSEAETQQPPAAPPC which corresponds to the $\mathrm{N}$ terminus of human YB-1 protein (accession number: P67809). The membrane was washed with TBST, followed by incubation with horseradish peroxidase-conjugated anti-rabbit IgG (1:6000; Sigma-Aldrich) for $1 \mathrm{~h}$ at room temperature. Specific binding was detected by enhanced chemiluminescence (Amersham Biosciences). The membrane was incubated with monoclonal mouse $\beta$-actin primary antibody (1:6000; Amersham Biosciences) for $1.5 \mathrm{~h}$ and horseradish peroxidaseconjugated anti-mouse IgG (1:10000; Amersham Biosciences) for $1 \mathrm{~h}$ at room temperature, which served as the loading control.

\section{Immunohistochemistry}

For immunohistochemical staining of nasopharyngeal cancer cells in vitro, CNE-2 nasopharyngeal cancer cells were seeded into a Lab-Tek ${ }^{\mathbb{R}} 4$-Chambered Coverglass (Nalge Nunc) at a density of $5 \times 10^{4}$ cells per ml. When cells have reached $70-80 \%$ confluency, they were fixed $1 \mathrm{ml}$ of cold $4 \%$ paraformaldehyde ( $\mathrm{pH} 7.4$ ) for $8 \mathrm{~min}$. For the human nasopharyngeal cancer tissues, paraffin sections were dewaxed in xylene, histoclear, equal parts histoclear and absolute ethanol, respectively, and rehydated with ascending series of ethanol. The sections were then heated in $10 \mathrm{mM}$ citrate buffer ( $0.1 \mathrm{mM}$ citric acid, $0.1 \mathrm{M}$ sodium citrate; $\mathrm{pH}$ 6.0) for $15 \mathrm{~min}$ in a $700 \mathrm{~W}$ microwave oven for the purpose of antigen retrieval. The slides were washed in PBSTX (0.05 M PBS, $0.1 \%$ Triton-X 100) thrice and then incubated with $3 \%$ hydrogen peroxide in methanol at room temperature for $15 \mathrm{~min}$ to quench endogenous peroxidase. The slides were then washed thrice with PBS-TX before incubation with 5\% normal goat serum for $1 \mathrm{~h}$ at room temperature to block nonspecific antibody binding, followed by incubation with primary anti-K13 antibody (1:300) overnight at room temperature. Detection of bound primary 
antibody was by adding biotinylated anti-rabbit immunoglobulin (1:200) for $45 \mathrm{~min}$ and avidinbiotin peroxidase complex (Vectastain ${ }^{\circledR}$ ABC Kit; Vector Laboratories) for $45 \mathrm{~min}$ at room temperature. The sections were visualized by incubating the slides in freshly prepared diaminobenzidine solution $\left(10 \times \mathrm{DAB}\right.$, TBS, $\left.30 \% \mathrm{H}_{2} \mathrm{O}_{2}\right)$ for $10 \mathrm{~min}$ and counterstained with Shandon's haematoxylin before mounting.

\section{Immunohistochemical Evaluation}

The stained slides were viewed using the $\times 10$ and $\times 40$ objective lens of a light microscope to determine the overall percentage and intensity of staining. YB-1 immunopositivity was defined as the presence of any specific staining in the cytoplasm and/or nucleus. The intensity of staining was scored as 0 (no detectable immunoreactivity), $1+$ (weak staining), $2+$ (moderate staining), and $3+$ (strong staining). The intensity-percentage score was derived from the product of staining intensity and percentage scores.

\section{Statistical Analysis}

The SPSS 12.0 statistical package was used for statistical analysis. The intensity-percentage score was dichotomized to categorize patients into those with an intensity-percentage score of $\geq 200$ (approximate topmost tertile) or $<200$ (lowest and middle tertiles). Correlations were examined using Fisher's exact test or Pearson's $\chi^{2}$-test and MannWhitney test or unpaired $t$-test. Recurrence-free survival and overall survival were determined using the Kaplan-Meier method and the survival curves were compared using log-rank statistics. Hazard ratios (and 95\% confidence intervals) of the association of high YB-1 immunoreactivity (intensitypercentage score $\geq 200$ ) with probabilities of recurrence and survival were estimated using Cox proportionate hazard regression models including age, sex, histopathological subtype, AJCC staging, and treatment as covariates. A $P$-value of $<0.05$ was considered significant.

\section{Results}

\section{Expression of YB-1 In Vitro}

CNE-2 nasopharyngeal cancer cells were found to have a higher level of $Y B-1$ mRNA expression (Figure 1a) although not statistically significant as compared to MDA-MB-231 breast cancer cells (which was used as a positive control). ${ }^{14,15}$ The specificity of the YB-1 and G3PDH primers were verified by melting curve analyses (not shown) and running the amplicons on a $1 \%$ gel (Figure $1 \mathrm{~b}$ ). The specificity of the anti-K13 antibody for human YB-1 protein in CNE-2 cells and MDA-MB-231 cells are a
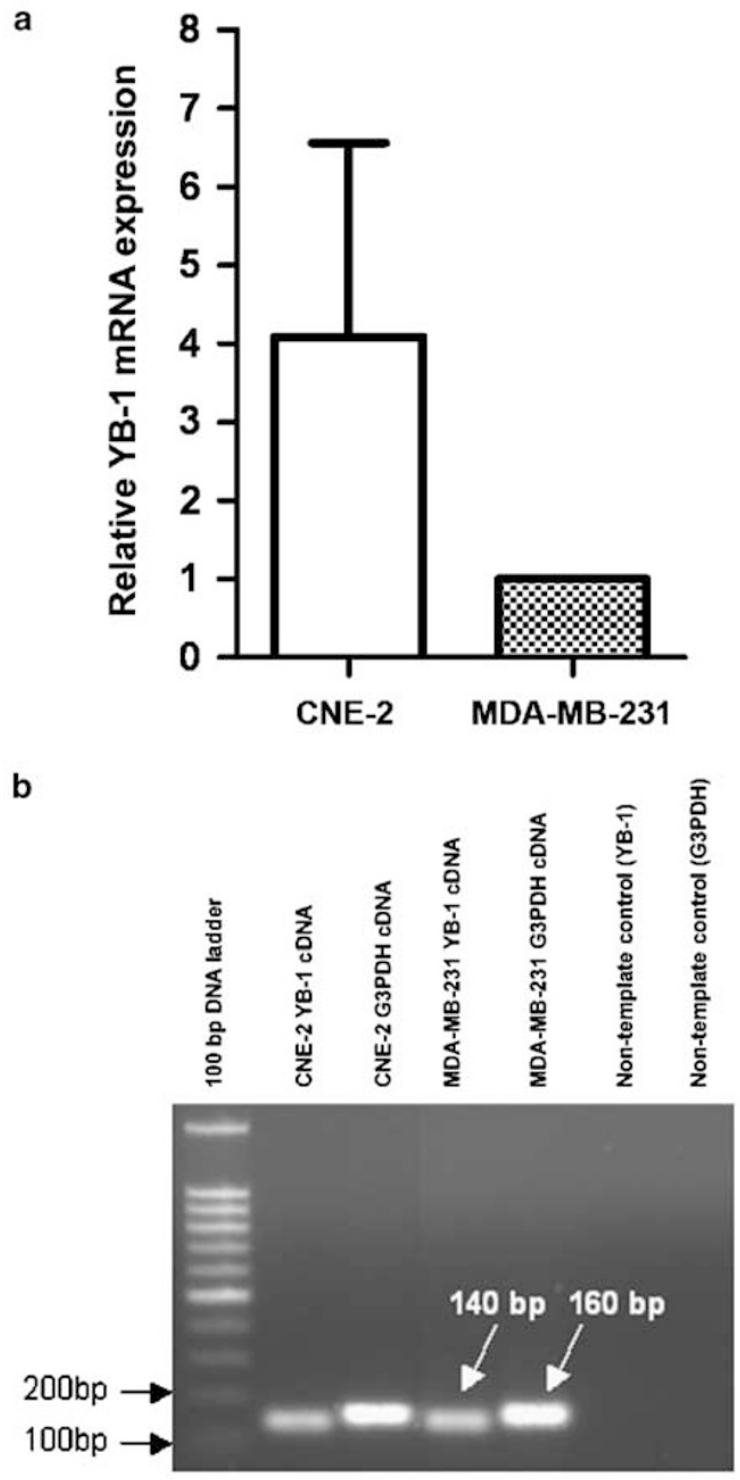

C

CNE-2 MDA-MB-231

YB-1

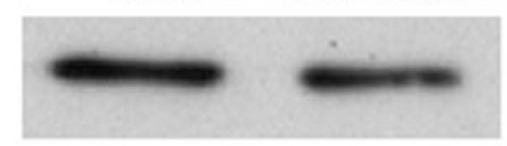

$50 \mathrm{kD}$

$\beta$-actin

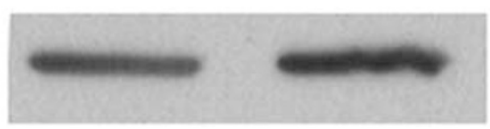

$43 \mathrm{kD}$

Figure 1 YB-1 expression in CNE-2 nasopharyngeal cancer cells. (a) YB-1 mRNA expression as determined by quantitative realtime RT-PCR. MDA-MB-231 breast cancer cells were designated as reference cell line. Relative mRNA expression is expressed as fold difference using the $2^{-\Delta \Delta C_{\mathrm{T}}}$ method. Columns, means of quadruplicate experiments; bars, s.e. (b) Gel electrophoresis photograph of real-time RT-PCR products depicting the $140 \mathrm{bp}$ amplicon of $Y B-1$ and the $160 \mathrm{bp}$ amplicon of G3PDH. No bands were detected for the negative controls. (c) Western blot analysis of YB-1 proteins in CNE-2 cells and MDA-MB-231 cells. Antibody against $\beta$-actin was incubated with the same blot for normalization of proteins loaded per well. A single band on the western blot corresponding to human YB-1 protein $(50 \mathrm{kDa})$ was observed in each lane. 
shown in Figure 1c. Positive YB-1 immunostaining in CNE-2 nasopharyngeal cancer cells was observed to be predominantly cytoplasmic (Figure 2a) with no staining seen in the negative control (Figure 2b).

\section{Immunohistochemical Analysis in Nasopharyngeal Cancer Patient Tumor Samples}

Of 143 patient tissue sections, 137 (96\%) were immunopositive for YB-1. Seven (4\%) nasopharyngeal cancer tissues showed negative YB-1 staining (Figure 2c). Among the YB-1-positive tumors, immunostaining was observed to be predominantly cytoplasmic and the intensity of staining was variable. A total of $36(25 \%)$ tissues had low YB-1 expression $(1+)$ (Figure 2d), 44 (31\%) with moderate expression $(2+)$ (Figure 2e) and $57(40 \%)$ with high expression $(3+)$ (Figure 2f).

\section{Association of YB-1 Immunohistochemical Staining With Clinicopathological Parameters}

There was no significant statistical correlation between high YB-1 expression (intensity-percentage score $\geq 200$ ) and gender, age, histopathological subtype, AJCC staging, tumor staging, nodal status and distant metastasis as seen in Table 1 (clinicopathological data was only available for 135 patients).

\section{Correlation of YB-1 Immunohistochemical Staining With Tumor Recurrence}

Tumors with higher YB-1 expression (median intensity-percentage $s c o r e=240$ ) as observed in pretreatment biopsies had a higher recurrence risk of nasopharyngeal cancer compared to those with lower expression (median intensity-percentage score $=97.5)(P<0.001$; Figure 3a). Within the group which received radiotherapy, $43(61 \%)$ of them had tumor recurrence. Thirty-two $(74 \%)$ of these patients with recurrence had high YB-1 expression (intensity-percentage score $\geq 200$ ). In addition, the median intensity-percentage score of patients who received radiotherapy and had tumor recurrence (intensity-percentage score $=270$ ) was found to be significantly higher than nonrecurrent cases (intensity-percentage score $=85) \quad(P<0.001$; Figure $3 \mathrm{~b})$. Of $64,24(38 \%)$ patients who were administered with chemoradiotherapy had tumor recurrence and within the tumor recurrence group, $10(42 \%)$ of them had high YB-1 expression (intensity-percentage score $\geq 200$ ). Moreover, the median intensity-percentage score in recurrent cases (intensity-percentage score $=185$ ) was significantly higher than that of nonrecurrent cases (intensity-percentage $\quad$ score $=82.5) \quad(P=0.0035$; Figure 3c).

The Cox proportionate hazard regression model also established that high YB-1 immunoreactivity (intensity-percentage score $\geq 200$ ) was significantly correlated with increased risk (2.13 times) of recurrence compared to low YB-1 immunoreactivity (intensity-percentage score $<200)(P=0.01$; Table 2). Gender, age, histopathological subtype, AJCC staging and treatment modality were treated as covariates. Hence, patients with a higher YB-1 expression in their pretreatment biopsies before radiotherapy or chemoradiotherapy had a higher risk of nasopharyngeal cancer recurrence after treatment.

Survival curves were plotted by the Kaplan-Meier method, and the statistical differences between the curves were evaluated by the log-rank test. A higher YB-1 expression (intensity-percentage score $\geq 200$ ) was associated with an increased probability of nasopharyngeal cancer recurrence (Figure 4a). On the other hand, there was no significant statistical correlation between high YB-1 expression and overall survival ( $P=0.56$; Figure $4 \mathrm{~b})$. This could, however, be due to the small number of deaths $(n=12)$ in this study.

\section{Discussion}

This is the first study to analyze YB-1 expression in human nasopharyngeal cancer tissues using molecular and immunohistochemical methods. Expression of YB-1 mRNA and protein were demonstrated in CNE-2 nasopharyngeal cancer cells which were derived from a patient with poorly differentiated nasopharyngeal cancer. This histological subtype accounts for more than $90 \%$ of all nasopharyngeal cancers diagnosed worldwide. ${ }^{16}$ In this study, more than $95 \%$ of the nasopharyngeal cancer tissues which were primarily WHO Type 3 nasopharyngeal cancer were observed to be positively stained for the YB-1 protein. The YB-1 staining was seen to be predominantly cytoplasmic in CNE-2 cells and nasopharyngeal cancer patient tissues. Studies conducted in breast cancer, non-small cell lung cancer, ovarian cancer and osteosarcoma have shown the presence of concomitant nuclear YB-1 expression together with cytoplasmic localization of the protein. ${ }^{12,17-19}$

We have not found distinct nuclear YB-1 staining in CNE-2 cells and nasopharyngeal cancer tissues. Although it is possible that the anti-K13 antibody which was used in this study, recognizes only the cytoplasmic epitope of YB-1, we consider the possibility unlikely because translocation of YB-1 to the nuclei in human HeLa cells has been detected by immunofluorescence using the same anti-YB-1 antibody (Matsumoto K, unpublished results). The YB-1 protein has been previously reported to be predominantly located in the cytoplasm in normal and tumor cells throughout the cell cycle (in association with an anchoring protein in the cytoplasm at a binding site on the C-terminal tail domain), but the protein is known to translocate into 


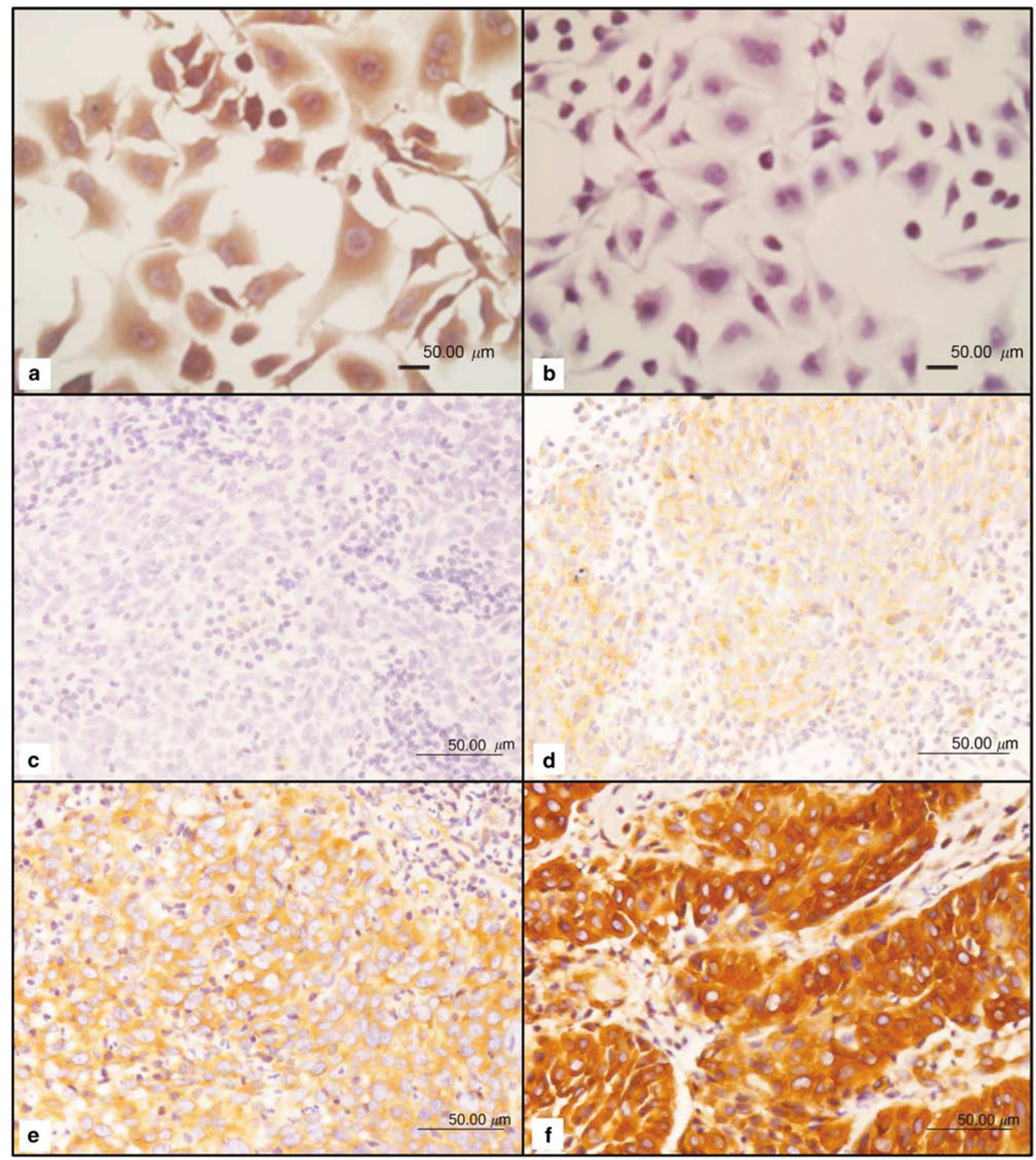

Figure 2 Immunohistochemical expression of YB-1 in CNE-2 cells and nasopharyngeal cancer tissue samples. (a) Predominantly cytoplasmic staining of YB-1 in CNE-2 cells. Nuclei counterstaining was performed using hematoxylin. (b) Negative control in CNE-2 cells. (c) Negative staining (intensity $=0$ ) in nasopharyngeal cancer tissues. (d) Weakly positive staining $(1+$ ) in nasopharyngeal cancer tissues. (e) Moderate staining $(2+)$ in nasopharyngeal cancer tissues. (f) Strong staining $(3+)$ in nasopharyngeal cancer tissues. Scale bars, $50 \mu \mathrm{m}$.

the nucleus during the $\mathrm{G}_{1}$ to $\mathrm{S}$ phase transition. ${ }^{20,21}$ Zhang et $a l^{22}$ have further demonstrated that nuclear localization of YB-1 requires wild-type p53.

YB-1 has been established as a prognostic marker in several human malignancies. Nuclear YB-1 expression has been linked to poorer prognosis compared to tumors with cytoplasmic YB-1 expression in breast cancer, non-small cell lung cancer, ovarian cancer, synovial sarcoma and hepatocellular carcinoma. ${ }^{15,17,18,23-25}$ Huang et $a l^{26}$ found a signifi- 

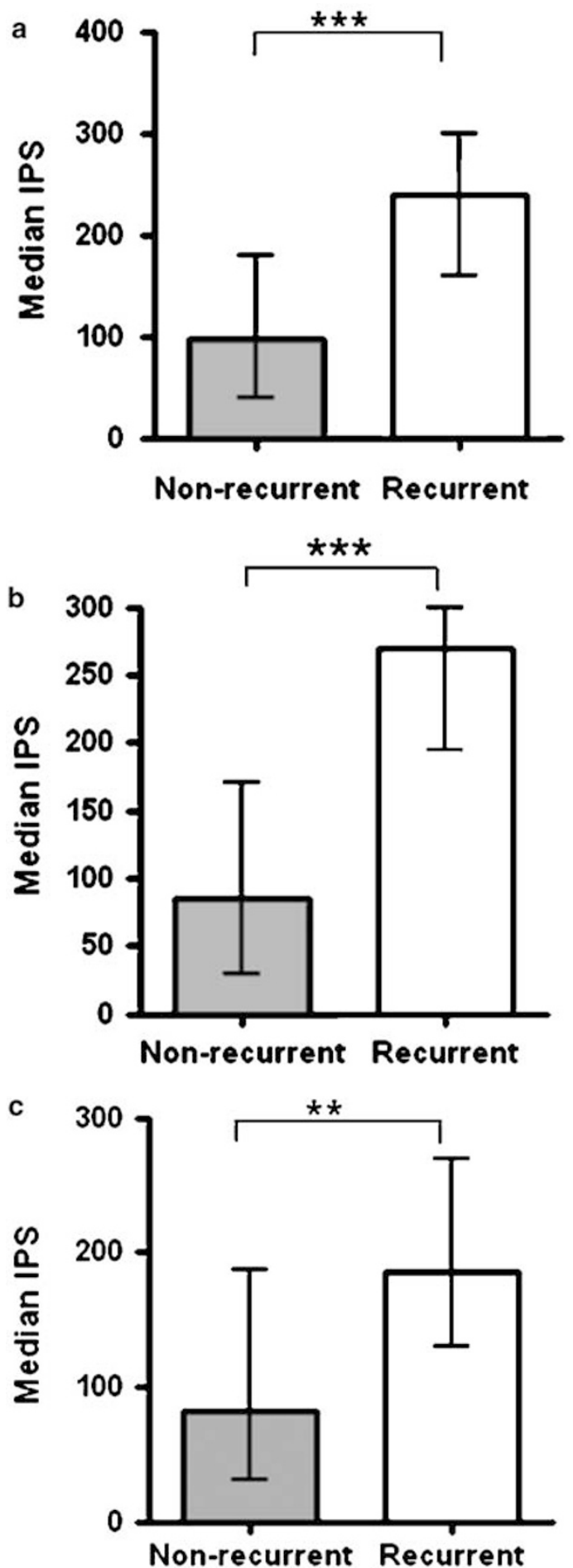

Figure 3 Median intensity percentage score of YB-1 immunostaining in non-recurrent and recurrent nasopharyngeal cancer cases. (a) All nasopharyngeal cancer patients. ${ }^{* * *} P$-value $<0.001$. (b) Nasopharyngeal cancer patients treated with radiotherapy. $* * * P$-value $<0.001$. (c) Nasopharyngeal cancer patients treated with chemoradiotherapy. ${ }^{*} P$-value $<0.01$.

cant correlation between coexpression of YB-1 and Pgp and poorer survival in ovarian cancer. In this study, YB-1 immunostaining had no significant correlation with age, sex, histopathological subtype, AJCC staging, tumor grade, nodal status and distant metastasis. However, we observed that high YB-1 expression was significantly associated with tumor aggressiveness and earlier tumor recurrence after therapy in nasopharyngeal cancer.

In this study, we showed that high YB-1 expression was significantly correlated with a reduction in radiosensitivity and chemoradiosensitivity, accounting for the high recurrence rate in nasopharyngeal cancer. YB-1 plays a significant role in the mediation of chemoresistance in many cancers, primarily by mechanisms involving mdr1 expres$\operatorname{sion}^{13,27,28}$ and increased potential of DNA repair by molecules such as DNA topoisomerase. ${ }^{28}$ There is also evidence that YB-1 binds specifically to RNA containing 8-oxoguanine, cisplatin-modified and apurinic DNA and interacts with proliferating cell nuclear antigen and p53, enhancing DNA repair. ${ }^{29-31}$

Recent biomarkers evaluated for predicting radiosensitivity and chemosensitivity in nasopharyngeal cancer include heat-shock protein Gp96 (HSP Gp96), growth differentiation factor 15 (GDF15), basic helixloop-helix transcription factor TWIST, cytokeratin 8 (CK 8), latent membrane protein-1 (LMP-1) and inhibitor of differentiation/DNA-binding 1 (Id-1). Gp96 which belongs to the HSP 9 family and GDF-15, a member of the transforming growth factor- $\beta$ superfamily were found to be upregulated in radioresistant nasopharyngeal cancer cell lines. ${ }^{32}$ Enhanced expression of TWIST and ectopic expression of Id-1 have been separately found to protect nasopharyngeal cancer cells from taxol-induced cell death. ${ }^{33-35}$ Wang et $a l^{36}$ have reported that silencing of the $C K 8$ gene increased cisplatin toxicity in HONE1 nasopharyngeal cancer cells. Mei et $a l^{37}$ have observed that there was enhanced chemosensitivity to bleomycin and cisplatin, following siRNA-mediated knockdown of LMP1 in EBV-positive C666-1 cells. To our knowledge, this is the first time that YB-1 has been reported to mediate radioresistance and chemoradioresistance in nasopharyngeal cancer.

A pervasive question on the minds of medical and radiation oncologists is how to identify patients with locally advanced nasopharyngeal cancer who could benefit from intensified systemic therapies. ${ }^{9}$ In this regard, YB-1 has the potential to be used as a biomarker to assess therapeutic efficacy and to predict treatment response, thus aiding selection of the most appropriate therapy to improve clinical outcome and minimize nasopharyngeal cancer recurrence. YB-1 could also be a promising target molecule for the development of novel combinatorial therapeutic strategies aimed at overcoming resistance to cancer therapy. Cisplatin-based combination therapy which is the current standard firstline therapy could potentially be more efficacious against advanced stage or recurrent nasopharyngeal cancer when combined with a strategy to inhibit YB-1 expression or abrogate its function. 
Table 2 Association of YB-1 intensity (intensity-percentage score $\geq 200$ ) with recurrence and survival

\begin{tabular}{|c|c|c|c|c|c|c|}
\hline & Wald statistic & Degree of freedom & $P$-value & Hazard ratio & \multicolumn{2}{|c|}{$95 \%$ confidence interval } \\
\hline Recurrence & 6.619 & 1 & 0.01 & 2.13 & 1.20 & 3.79 \\
\hline Survival & 0.344 & 1 & 0.56 & 1.68 & 0.30 & 9.54 \\
\hline
\end{tabular}

${ }^{\mathrm{a}}$ Test of significance of the regression coefficient.

a

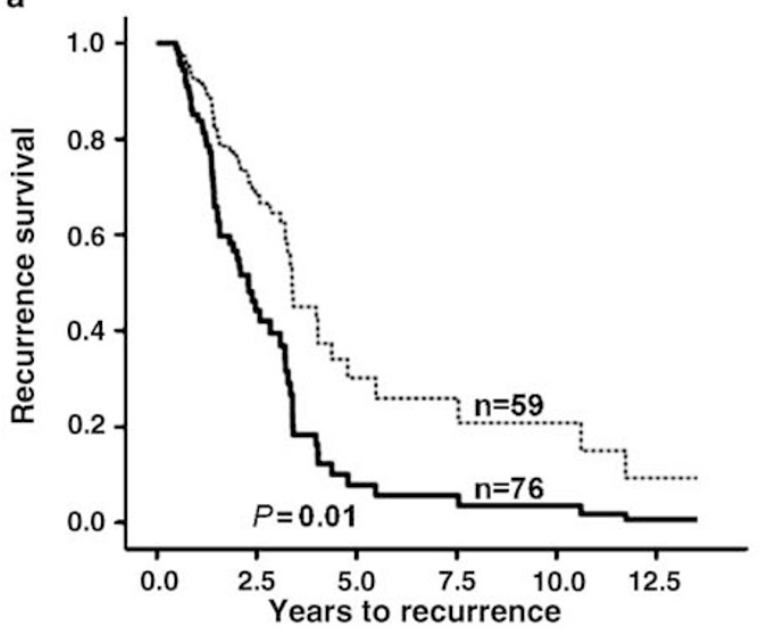

b
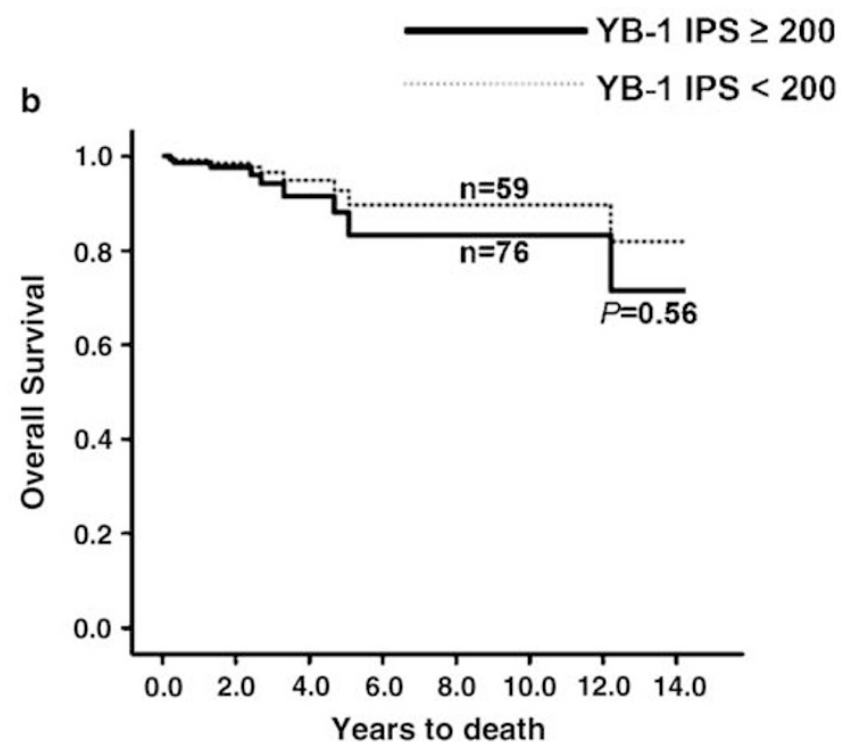

Figure 4 Kaplan-Meier plots of (a) recurrence-free survival and (b) overall survival in nasopharyngeal cancer patients with follow-up data $(n=134)$.

\section{Acknowledgements}

We are grateful to Dr Joseph Wee, National Cancer Centre of Singapore (NCC) for his advice, Dr M Olivo (NCC) for the gift of the CNE-2 cell line and Ms SL Bay for technical assistance. This project was supported by the Singapore National Medical Research Council Grant NMRC/1019/2005 (B-HB) and the Singapore Cancer Syndicate MS0004 and MS 04R (P-HT).

\section{Disclosure/conflict of interest}

None.

\section{References}

1 Ferlay J, Bray F, Pisani P, et al. Globocan 2000: Cancer Incidence, Mortality and Prevalence Worldwide (Version 1.0). IARC Cancer Base No. 5. IARC Press: Lyon, 2001.

2 Chan JKC, Pilch BZ, Kuo TT, et al. Tumours of the nasophrynx: introduction. In: Barnes L, Eveson JW, Reichart P, Sidransky D (eds). World Health Organization Classification of Tumours. Pathology and Genetics of Head and Neck Tumours. IARC Press: Lyon, 2005, pp 83-84.
3 Marks JE, Phillips JL, Menck HR. The national cancer database report on the relationship of race and national origin to the histology of nasopharyngeal carcinoma. Cancer 1998;83:582-588.

4 Lo KW, To KF, Huang DP. Focus on nasopharyngeal carcinoma. Cancer Cell 2004;5:423-428.

5 Lee AW. Contribution of radiotherapy to function preservation and cancer outcome in primary treatment of nasopharyngeal carcinoma. World J Surg 2003;27:838-843.

6 Reddy SP, Raslan WF, Gooneratne S, et al. Prognostic significance of keratinization in nasopharyngeal carcinoma. Am J Otolaryngol 1995;16:103-108.

$7 \mathrm{Ma} \mathrm{BB}$, Hui EP, Chan AT. Systemic approach to improving treatment outcome in nasopharyngeal carcinoma: current and future directions. Cancer Sci 2008;99:1311-1318.

8 Teo PM, Chan AT. Treatment strategy and clinical experience. Semin Cancer Biol 2002;12:497-504.

9 Guigay J. Advances in nasopharyngeal carcinoma. Curr Opin Oncol 2008;20:264-269.

10 Kohno K, Izumi H, Uchiumi T, et al. The pleiotropic functions of the Y-box binding protein YB-1. Bioessays 2003;25:691-698.

11 Matsumoto K, Wolffe AP. Gene regulation by Y-box proteins: coupling control of transcription and translation. Trends Cell Biol 1998;8:318-323.

12 Bargou RC, Jürchott $\mathrm{K}$, Wagener $\mathrm{C}$, et al. Nuclear localization and increased levels of transcription factor 
YB-1 in primary human breast cancers are associated with intrinsic MDR1 gene exprsesion. Nat Med 1997;3:447-450.

13 Ohga T, Uchiumi T, Makino Y, et al. Direct involvement of the Y-box binding protein YB-1 in genotoxic stress-induced activation of the human multidrug resistance 1 gene. J Biol Chem 1998;273:5997-6000.

14 Huang JX, Tan PH, Li KB, et al. Y-box binding protein, YB-1, as a marker of tumor aggressiveness and response to adjuvant chemotherapy in breast cancer. Int J Oncol 2005;26:607-613.

15 Janz M, Harbeck N, Dettmar P, et al. Y-box factor YB-1 predicts drug resistance and patient outcome in breast cancer independent of clinically relevant tumour biologic factors HER2, uPA and PAI-1. Int J Cancer 2002;97:278-282.

16 Zhang S, Gao X, Zeng Y. Cytogenetic studies on an epithelial cell line derived from poorly differentiated nasopharyngeal carcinoma. Int J Cancer 1983;31:587-590.

17 Shibahara K, Sugio K, Osaki T, et al. Nuclear expression of the Y-box binding protein, YB-1, as a novel marker of disease progression in non-small cell lung cancer. Clin Cancer Res 2001;7:3151-3155.

18 Kamura $\mathrm{T}$, Yahata $\mathrm{H}$, Amada $\mathrm{S}$, et al. Is nuclear expression of $\mathrm{Y}$ box-binding protein protein-1 a new prognostic factor in ovarian serous adenocarcinoma? Cancer 1999;85:2450-2454.

19 Oda Y, Sakamoto A, Shinohara N, et al. Nuclear expression of YB-1 protein correlates with P-glycoprotein expression in human osteosarcoma. Clin Cancer Res 1998;4:2273-2277.

20 Jürchott K, Bergmann S, Stein U, et al. YB-1 as cell cycle regulated transcription factor facilitating cyclic A and cyclin B1 gene expression. J Biol Chem 2003;278:27988-27996.

21 Koike K, Uchiumi T, Ohga T, et al. Nuclear translocation of the Y-box binding protein by ultraviolet irradiation. FEBS Lett 1997;417:390-394.

22 Zhang YF, Homer C, Edwards SJ, et al. Nuclear localization of Y-box factor YB1 requires wild-type p53. Oncogene 2003;22:2782-2794.

23 Gessner C, Woischwill C, Schumacher A, et al. Nuclear YB-1 expression as a negative prognostic marker in non-small cell lung cancer. Eur Respir J 2004;23:14-19.

24 Oda Y, Ohishi Y, Saito T, et al. Nuclear expression of Ybox-binding protein-1 correlates with P-glycoprotein and topoisomerase II $\alpha$ expression, and with poor prognosis in synovial sarcoma. J Pathol 2003;199:251-258.

25 Yasen M, Kajino K, Kano S, et al. The up-regulation of Y-box binding proteins (DNA binding protein A and Y-box binding protein-1) as prognostic markers of hepatocellular carcinoma. Clin Cancer Res 2005;11:7354-7361.
26 Huang X, Ushijima K, Komai K, et al. Co-expression of $\mathrm{Y}$ box-binding protein 1 and P-glycoprotein as a prognostic marker for survival in epithelial ovarian cancer. Gynecol Oncol 2004;93:287-291.

27 Kuwano M, Oda Y, Izumi H, et al. The role of nuclear Y-box binding protein 1 as a global marker in drug resistance. Mol Cancer Ther 2004;3:1485-1492.

28 Chaudhary PM, Roninson LB. Induction of multidrug resistance in human cells by transient exposure to different chemotherapeutic drugs. J Natl Cancer Inst 1993;85:632-639.

29 Hasegawa SL, Doetsch PW, Hamilton KK, et al. DNA binding properties of $\mathrm{YB}-1$ and $\operatorname{dbpA}$ : binding to double-stranded, single-stranded, and abasic site containing DNAs. Nucleic Acids Res 1991;19: 4915-4920.

30 Ise T, Nagatani G, Imamura T, et al. Transcription factor Y-box binding protein 1 binds preferentially to cisplatin-modified DNA and interacts with proliferating cell nuclear antigen. Cancer Res 1999;59: 342-346.

31 Okamoto $\mathrm{T}$, Izumi $\mathrm{H}$, Imamura $\mathrm{T}$, et al. Direct interaction of p53 with the Y-box binding protein, YB-1: a mechanism for regulation of human gene expression. Oncogene 2000;19:2955-2966.

32 Chang JT, Chan SH, Lin CY, et al. Differentially expressed genes in radioresistant nasopharyngeal cancer cells: gp96 and GDF15. Mol Cancer Ther 2007;6:2271-2279.

33 Wang X, Ling MT, Guan XY, et al. Identification of a novel function of TWIST, a bHLH protein, in the development of acquired taxol resistance in human cancer cells. Oncogene 2004;23:474-482.

34 Cheung HW, Ling MT, Tsao SW, et al. Id-1-induced Raf/MEK pathway activation is essential for its protective role against taxol-induced apoptosis in nasopharyngeal carcinoma cells. Carcinogenesis 2004;25:881-887.

35 Zhang X, Wang Q, Ling MT, et al. Anti-apoptotic role of TWIST and its association with Akt pathway in mediating taxol resistance in nasopharyngeal carcinoma cells. Int J Cancer 2007;120:1891-1898.

36 Wang Y, He QY, Tsao SW, et al. Cytokeratin 8 silencing in human nasopharyngeal cells leads to cisplatin sensitization. Cancer Lett 2008;265:188-196.

37 Mei YP, Zhou JM, Wang Y, et al. Silencing of LMP1 induces cell cycle arrest and enhances chemosensitivity through inhibition of AKT signaling pathway in EBV-positive nasopharyngeal carcinoma cells. Cell Cycle 2007;6:1379-1385. 